\title{
Parental authoritarian style influence on the children behavior in dental office
}

\author{
Milena Georgieva, Milena Peneva \\ Department of Pediatric Dentistry, Faculty of Dental \\ Medicine, Medical University of Sofia
}

\section{Abstract}

The aim of this study is to investigate the correlation between authoritarian style of the parents and the negative behavior in their children in dental office.

Methods and materials: Influence of the authoritarian style on children's behavior in dental office was determined in 300 children and their parents, who signature inform consent. There are eight questions which determined authoritarian parents' style, which characterized different aspects of parenting. They are adopted for parents and children. The real presence of that education was found by correlation between answers of parents and children. It was established that $41,42 \%$ of children give evidence for presence of authoritarian parents' style. Reliable lower numbers of parents (37\%) give answers, which characterized this style. Index for positive authoritarian style for children is reliable higher than parents' index. This indicates that children are more sensitive to authoritarian style than the parents realized.Conclusion: Most of the children rearing in authoritarian style have negative behavior.

\section{Keywords: authoritarian style, rearing, behavior}

\section{Introduction}

Authoritarian style reveals powerful parent's figure, who uses strong rules in child rearing (1). This parents do not give opportunity for choice, but create habits and values for children.

Authoritarian parenting is a style characterized by high demands and low responsiveness. Parents with an authoritarian style have very high expectations of their children, yet provide very little in the way of feedback and nurturance. Mistakes tend to be punished harshly $(2,3)$. When feedback does occur, it is often negative Yelling and corporal punishment are also commonly seen with the authoritarian style $(2,3)$. 
The children of authoritarian parents may act fearful or overly shy around strangers, have difficulty in social situation, may lack self-discipline $(4,5)$. Children behavior towards adults varies according to different parent's style and that behavior continues in the dental office and may influence the complicated patient-parent-dentist interaction $(6,7,8)$. It is interesting to check if this rearing style create confident children, who are prepared for adequate reaction in dental office or they are more likely to become anxious and with negative behavior.

\section{Aim}

The aim of this study is to investigate the correlation between authoritarian style of the parents and the negative behavior in their children in dental office.

\section{Material and Methods}

This study was conducted among 300 children aged between 4 and 6 and their parents. Parents were asked to fill out a questionnaire about their child rearing practice. It includes basic information that covers family data, family structure, decision making process for having children, child care, type of family structure, attitudes about parenting experiences, family values and family rituals. The questions were completed while waiting for their child during the examination in dental office. Parents are asked to rate the extent to which the item represents their typical response of a 5 point scale ranging from 0 (never) to 5 (always). For example, 'often use strict punishment' correlates to the authoritarian parenting style, while 'give our child reasons why rules should be obeyed' correlates to the authoritative parentingstyle. Total results are summated to create a total score. A higher score reflected a higher use of authoritarian parenting on the child's behavior.

The Frankle scale was used to rate patient behavior using categories ofdefinitely negative, negative, positive, and definitely positive.

After assessment of children behavior, children were asked about different aspect in parenting and the behavior of their parents toward them. Children were asked about the same behavior but in a different way in order to check the parents answer. Questions were designed regarding parents' attitudes and behavior. After examination the answers were filled in by the dentist. Both questionnaries of parents and children were with the same number.

The data collected were analyzed using SPSS Program version 19. The Chi-square test was used to detect differences between various distributions and the P-value was set at $<0.05$ for significance throughout the study. 


\section{Results and discussion}

The answers of both children and parents which determined authoritarian parenting were related.

Table 1. Common results in authoritarian parenting for parents and children

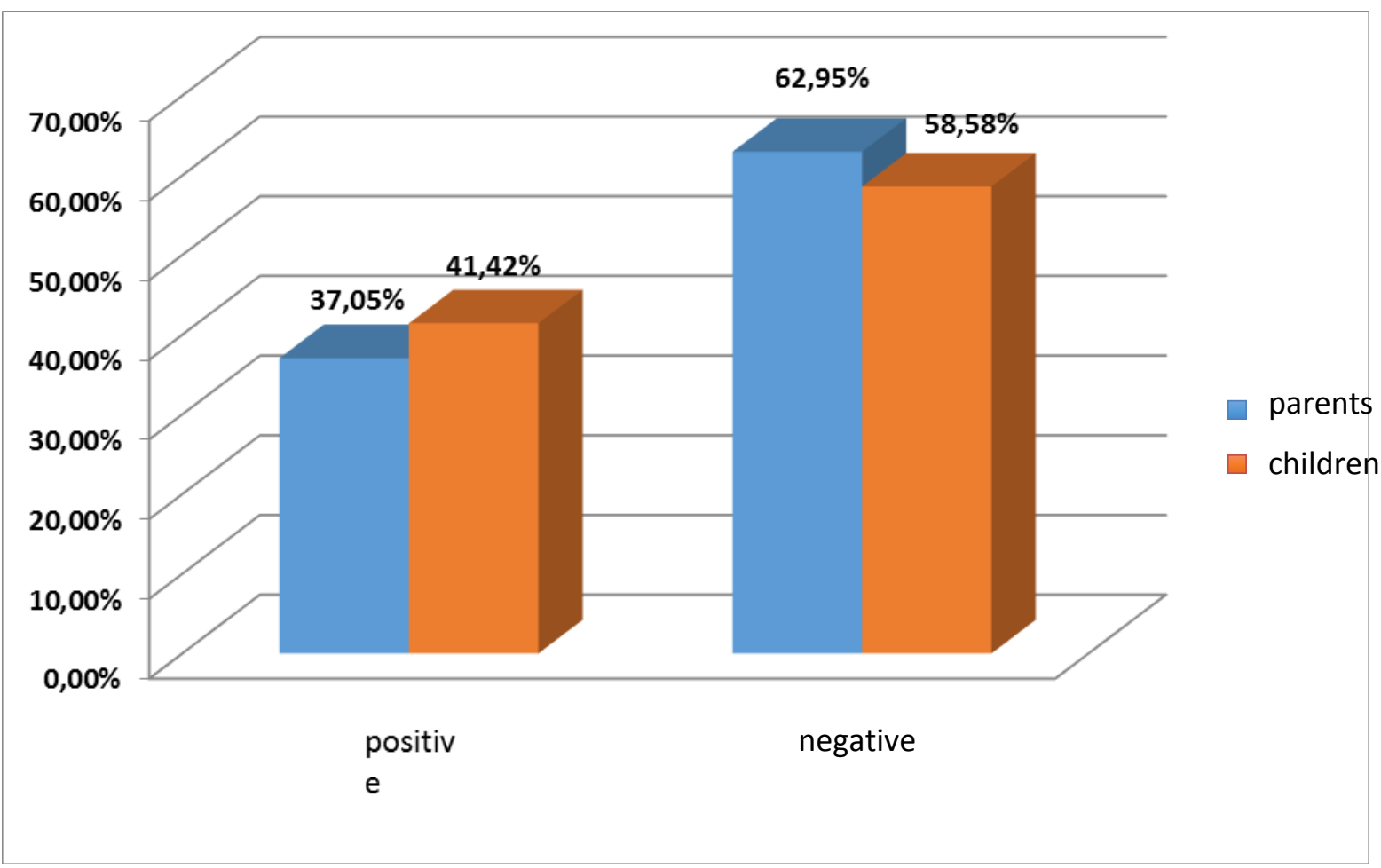

Results show that most children evaluate parents' behavior toward them as authoritarian in comparison with the results of their parents for the same rearing style (Table 1). A statistically significant difference was found in the distribution of authoritarian style depending on the children and parents answers $(P<$ 0.0001 , Table 2). About $41,42 \%$ from all children are positive for authoritarian behavior. Significantly lower percent of the parents $37 \%$ gave answers, which characterized this behavior (Table 1). The result indicates that children rising with authoritarian methods have a significantly higher sensitivity to this behavior than the parents think. This is explained by the fact that most parents do not discuss the negative effect of parenting with their child. 
Table 2. Parents' and children's results for authoritarian behavior

\begin{tabular}{|c|c|c|c|c|}
\hline $\begin{array}{l}\text { Common } \\
\text { children }\end{array}$ & Positive & Negative & Common & $t, p$ \\
\hline Answer number & 870 & 1230 & 2100 & \multirow{6}{*}{$\begin{array}{l}p<0,05 \\
t=37,5 \\
p<0,0001\end{array}$} \\
\hline$\%$ & $41,42 \%$ & 58,58 & $100 \%$ & \\
\hline Points number & 1740 & 1230 & 2907 & \\
\hline $\mathrm{X}$ & 2 & 1 & 1,38 & \\
\hline SD & 0 & 0 & 0,61 & \\
\hline Index & 5 & 2,5 & 3,45 & \\
\hline \multicolumn{5}{|l|}{ Common parents } \\
\hline Answer number & 778 & 1322 & 2100 & \multirow[t]{5}{*}{$\begin{array}{l}t=36,29 \\
p<0,0001\end{array}$} \\
\hline$\%$ & $37,05 \%$ & $62.95 \%$ & $100 \%$ & \\
\hline Points number & 3164 & 2366 & 5672 & \\
\hline $\mathrm{X}$ & 4,06 & 1,78 & 2,70 & \\
\hline SD & 0,77 & 0,98 & 1,01 & \\
\hline
\end{tabular}

The results which show that children are more sensitive to authoritharian behavior are confirmed with lowest statistically significant correlation $(t=1,82, p<0,05)$ (Table 2$)$. Index for authoritarian rearing style is significant higher in children's answer than in parent's answer $(t=36,29, p<0,001)$ (Table 2).

Searching for correlation between parents' style and children's negative behavior, we divided parent's answers into four groups according to child's behavior in the dental office. The results show which questions are correlated with negative behavior (Table 3). 
I S S U 2,2016

Table 3. Correlation between parents' rearing style and children behavior using Frankle style

\begin{tabular}{|c|c|c|c|c|c|c|c|c|c|c|c|}
\hline $\begin{array}{l}\text { № } \\
\text { question }\end{array}$ & $\begin{array}{l}\mathrm{Fr}=1 \\
\mathrm{n}=24 \\
\mathrm{x}\end{array}$ & SD & $\begin{array}{l}\mathrm{Fr}=2 \mathrm{n}= \\
106 \\
X\end{array}$ & SD & $\begin{array}{l}\mathrm{Fr}=3 \\
\mathrm{n}=131 \\
\mathrm{x}\end{array}$ & SD & $\begin{array}{l}F r=4 \\
n=39 \\
x\end{array}$ & SD & $\begin{array}{l}\text { common } \\
n=300 \\
x\end{array}$ & SD & $\mathrm{T}, \mathrm{p}$ \\
\hline $1 *$ & 3,33 & 1,1 & 2,89 & 1,28 & 3,04 & 1,32 & 2,82 & 1,17 & 3,00 & 1,01 & $\begin{array}{l}\mathrm{T} 1,4=1,96 \\
\mathrm{p}<0,05\end{array}$ \\
\hline $2 * *$ & 3,29 & 1,39 & 3,60 & 1,22 & 3,63 & 1,22 & 3,94 & 1,29 & 3,64 & 1,26 & $\begin{array}{l}\mathrm{T} 1,4=1,86 \\
\mathrm{p}<0,05\end{array}$ \\
\hline $4 * * *$ & 3,83 & 1,06 & 3,96 & 0,98 & 3,89 & 0,98 & 4,25 & 0,92 & 3,97 & 0,98 & $\mathrm{~T} 1,4=2,5$ \\
\hline $6 * * * *$ & 3,45 & 1,07 & 3,43 & 1,04 & 3,36 & 1,08 & 3,12 & 1,11 & 3,36 & 1,07 & $\mathrm{~T} 1,4=1,95$ \\
\hline $9^{* * * * *}$ & 3,41 & 1,07 & 2,98 & 0,95 & 3,16 & 1,05 & 2,87 & 1,04 & 3,07 & 1,03 & $\mathrm{~T} 1,4=2$ \\
\hline $\begin{array}{l}13^{* * * *} \\
* *\end{array}$ & 4,62 & 0,56 & 4,27 & 1,00 & 4,2 & 1,01 & 4,35 & 1,09 & 4,29 & 0,99 & $\mathrm{~T}=3,23$ \\
\hline $\begin{array}{l}20 * * * * \\
* * *\end{array}$ & 3,95 & 0,97 & 3,57 & 1,17 & 3,48 & 1,14 & 3,25 & 1,23 & 3,51 & 1,16 & $\mathrm{~T}=2,59$ \\
\hline $\begin{array}{l}25 * * * * \\
* * * *\end{array}$ & 2,12 & 0,92 & 1,78 & 0,88 & 2,01 & 1,05 & 1,66 & 0,63 & 1,89 & 0,95 & $\mathrm{~T}=2,12$ \\
\hline $\begin{array}{l}28 * * * * \\
* * * * *\end{array}$ & 3,75 & 0,92 & 4,16 & 0,95 & 4,26 & 0,92 & 4,35 & 0,83 & 4,21 & 0,93 & $\mathrm{~T}=2,72$ \\
\hline
\end{tabular}

*1. Do you use phrase "because I said so" to make you child do something? ${ }^{\star \star} 2$. Do you explain reasons behind your expectation? ${ }^{* \star *} 4$. Do you think that all the problems have some solutions? ${ }^{* \star \star *} 6$. Are you irritated from the mess at home? ${ }^{\star \star \star \star \star} 9$. Are you angry when the child disobeys the rules? ${ }^{\star \star \star \star \star \star} 13$. Are you too anxious about health problems? $\star \star \star \star \star \star \star \star 20$. Do you think that physical punishment is good for discipline? ${ }^{\star \star \star \star \star \star \star \star} 25$. Do you have great expectations

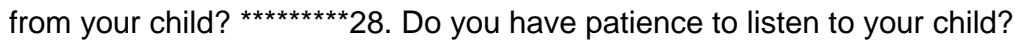

Parent's and children's answers were analyzed to explore the correlation between certain elements of parenting and children's behavior. There are nine questions, which are connected with risky elements of parents' style. These questions concern parent's anxiety, irritation, explanation of good and bad behavior, optimism, high expectation, patience to listen and punishment.

First question reveals the behavior of authoritarian parents who don't encourage an independence, but want to control everything. This is linked with less self-reliance, worse problem solving, and worse emotional health of children. The independence influences how a child copes with stresses and stimuli, like in a dental settings. Less independence is linked with inability to cope with the stress during treatment. For proper explanation about right and wrong actions showed a significant correlation between parents and child behavior. More good reasoning in the right manner shown by the parents was associated with positive behavior to dental treatment by their child. Parents who guided the child in making sound, healthy, life decisions through open communication and mutual respect influenced their children's motivation and 
coping with dental treatment.This is a part of authoritative parent's style. Our research indicated an association between authoritative and more cooperative patient behavior in the dental office. Those children whose parents reported higher positive disposed reported to be anxiety-free, confident and positive to dental treatment.

Negative parental behavior is associated with negative behavior in children in dental office. Parental negativism may result in decreased protection, caregiving, and discipline for the child, thereby placing the child at risk for a wide variety of emotional and behavior problems. Irritation and angriness is also parental attitudes which leads to negative children behavior. Parents who are anxious may transmit their own dental anxiety or fear to the child thereby adversely affecting her attitude and response to dental care.

Results show lower correlation with usage of physical punishment as a discipline method. The authoritative parents use them, but they show also lack of patience, lack of explanation and good communication to convince child to do something. This kind of discipline leads to anger, fear and negative behavior, which could complicate the visit in dental office, especially if the child did not want to cooperate. Next two questions are elements of overprotective and authoritative parents' style. They are about great parents' expectation and patience to listen to the child needs and feelings. Negative behavior is associated with higher parent's expectation and lack of patience to communicate with a child.Unrealistic expectations about child abilities are related to child's resistant behavior. Presence of overprotective rearing leads to impossibility for coping with new experience.

\section{Conclusion}

Authoritarian parenting is risky for development of negative behavior while authoritative is associated with more cooperative patient behavior in the dental office. Parents should be a partner in behavior guidance of the child whose role should be guided by the dentist. In order to do this dentist should recognize the ways in which the parents influence the child's behavior.

\section{References}

1. Bornstein, M. Handbook on Parenting: children and parenting. Mahwah NJ: Lawrence Erlbaum Publishers, 2002. 1.

2. Baumrind, D. The influence of parenting style on adolescent competence and substance use. Journal of Early Adolescence, 1991, 11(1), 56-95.

3. Maccoby, E.E.The role of parents in the socialization of children: An historical overview. Developmental Psychology, 28, 1992, 1006-1017.

4. Santrock, J.W. A Topical Approach to Life-span Development, Third Ed. New York: McGraw-Hill, 2007.

5. Stassen Berger, K. The Developing Person Through the Lifespan.2011, New York: Worth Publishers.

6. Aminabadi, N.A. and R.M. Farahani, Correlation of parenting style and pediatric behavior guidance strategies in the dental setting: preliminary findings. Acta Odontol Scand, 2008. 66(2): p. 99-104 
7. Sheller, B., Challenges of managing child behavior in the 21st century dental setting. Pediatr Dent, 2004. 26(2): p. 111-113.

8. Wright GZ, S.J., Nonpharmacologic management of children's behavior., in McDonald and Avery's Dentistry for the Child and Adolescent. 2011, MosbyElsevier: Maryland Heights, MO. p. 13

\section{Corresponding author:}

Milena Georgieva

Faculty of Dental Medicine,

Medical University of Sofia

Georgi Sofiiski Str.1, 1431 Sofia, Bulgaria

Email: mmeni@abv.bg 